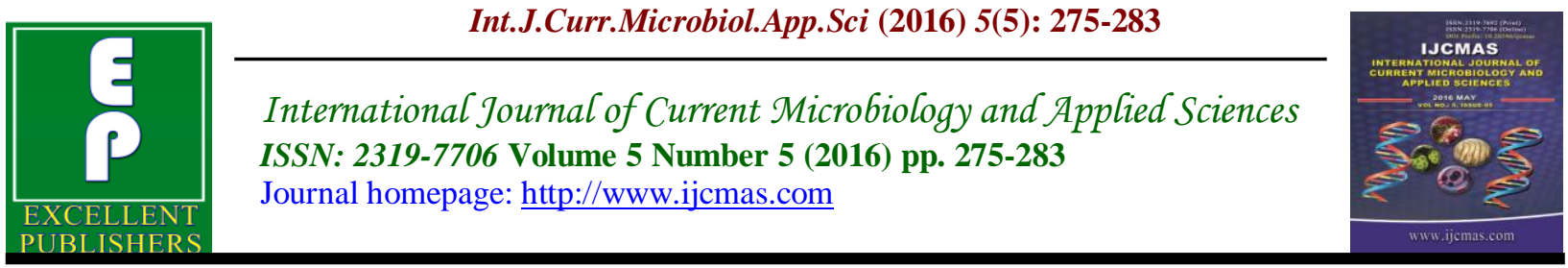

Original Research Article

http://dx.doi.org/10.20546/ijcmas.2016.505.030

\title{
Biochemical Detection of Phenolic Compounds and Peroxidase in New Locally Improved Tomato Lines by using HPLC
}

\author{
Mosaad F. Ahmed*, Hanafy A. Hamza, Ibrahiem A. Ibrahim, \\ A.A. Nower and Mostafa Alansary \\ Plant Biotechnology Department, Genetic Engineering and Biotechnology Research \\ Institute, University of Sadat City, Egypt \\ *Corresponding author
}

\begin{abstract}
A B S T R A C T
Keywords

Tomato breeding,

Fusaruim

resistance

phenolic

compounds

peroxidases

activity

HPLC.

\section{Article Info}

Accepted:

15 April 2016

Available Online:

10 May 2016

Fifteen different tomato genotypes obtained from breeding program were screened to evaluate their tolerant potential toward Fusarium wilt disease under green house conditions. Relation between tolerant potential of tested tomato genotypes toward Fusarium oxysporum fsp.lcyopersici and accumulation of peroxidase enzyme as well as polyphenolic compounds was achieved through bio-chemical analysis investigations using high pressure liquid chromatogram (HPLC) under in vitro conditions. The results showed that the most tolerant tomato genotypes to pathogenic Fusarium showed the highest ability to produce either peroxidases or polyphenolic compounds under the test conditions. Thus the accumulation of antioxidant enzymes, peroxidases, and polyphenols was negative proportionally with reduction of Fusarium wilt disease severity. Although, the highest growth criteria were recorded within genotypes produced the highest amount of both peroxidase and polyphenols. In conclusion, significant variation among the obtained tomato genotypes from the breeding program was detected with regard to their natural tolerant ability against Fusarium oxysporum. According to biochemical assay using HPLC, there is, for some extent, an evidence for positive correlation between natural ability of tested tomato genotypes to produce peroxidase and polyphenols compounds and the resistance against Fusarium wilt disease which point to a possible correlation between phenolic and peroxidase anti oxidant enzyme and tolerance potential of tomato genotypes toward hazardous pathogens like Fusarium species.
\end{abstract}

\section{Introduction}

Vegetables are the most important food crops in the world, supplying human with both energy and a wide array of nutrients. Total world vegetable production was estimated to be 916 million tons in 2008 (FAO 2008, Agricultural Statistics).
Tomato (Solanum lycopersicum L.) is the most important vegetable grown for human consumption. This crop has an increasing importance especially in those countries with rapidly expanding populations, e.g. Africa and Asia, where tomato production was increased since 1990 by 32 and 50 
percent, respectively (Sikora and Fernandez, 2005).

The global production of tomatoes was duplicated three times in the last 4 decades (FAO 2003, Agricultural Statistics) which is an indication of its importance as a major food crop. World production of tomato covers approximately 4 million hectares of arable land with production estimated at 100.5 million tons and valued at 5-6 billion US\$ (Costa and Heuvelink, 2005).

Tomato is also a versatile crop that can be classified according to use into fresh market tomatoes and processing tomatoes which are cultivated for industrial canning and processed foods. Many soil macro and micro organisms are parasites or pathogens of a wide spectrum of vegetable plants where they can cause severe crop losses (Noling, 2005). Since 1895, when Fusarium oxysporum f.sp. lycopersici was identified in England, it was considered the most dominant and destructive tomato pathogen. Beside, tomato plants, it can attack a wide range of economically important crops where this fungus can affect both yield and quality. It has been estimated that Fusarium wilt disease caused by Fusarium oxysporum is only responsible for 10 to $50 \%$ of these losses (Lukyanenko, 1991).

Vegetables in general are known to be extremely susceptible to Fusarium infection especially in both tropical and subtropical areas where vegetable production is severely limited by this pathogen. In Egypt, the losses due to tomato wilt disease reached up to $67 \%$ (Lasheen, 2009). Different control methods are used in the integrated management of plant pathogens on vegetables. Chemical control, solarization, rotation, steam heating and resistant cultivars are management methods in wide use. However, all of these management tools have limitations.
The use of chemical control which depends on using fumigation or systemic fungicides is often restricted due to high costs and/or adverse effects on environment and human health.

Agricultural practices like crop rotation, flooding, steam and solar heating as well as fallowing that have been traditionally used in integrated pest management also have become less usable because of pressure on land and economic demands for more intensification and mass-production of crops and the costs involved that reduces profits.

However, these limitations on standard control tools make the use of resistant cultivars, which should be a major tool in management of Fusarium wilt disease on vegetable crops, is unique and remarkable as one of most promising control techniques.

The resistance to Fusarium wilt disease is related to a single group of $i$-genes (Immune genes) (Yaghoobi et al., 1995; Veremis and Roberts, 1996a,b; Williamson, 1998). Important fact is that $i$-resistance to Fusarium can be broken-down under temperatures above $28 \mathrm{C}^{\circ}$. This limiting factor affects many tomato crops grown in warm tropical and sub tropical regions that are affected by virulent Fusarium races in the field (Roberts and Thomason, 1989). Therefore, new sources of resistance to Fusarium oxysporum are still needed to improve pest management programs on all vegetable crops (Hussey and Janssen, 2002). Sikora and Fernandez (2005) also reported that $i$-genes based resistance can be broken by new pathotypes.

Detection and development of tomato genotypes requires understanding of the mode of action and the nature of resistance activity against hazardous pathogens and parasites. 
Different mechanisms of action were reported in interactions between host plant and pathogen and considered responsible for protecting the host plants including: accumulation of antioxidant compounds and induction of host plant defences (Alabouvette et al., 1998; Fravel et al., 2003; Fuchs et al., 1997).

Little is known, however, about the exact mechanism of action involved in interactions between tomato plants and the Fusarium oxysporum f.sp.lycopersici. There is an evidence that different metabolites are involved in some of these interactions and that the substances influence defence signals and regulation of the symbiosis (Schulz and Boyle, 2005).

The present study was initiated to:

Screen different local tomato genotypes obtained from local breeding program in aspect to their tolerant potential against Fusarium oxysporum infection under green house conditions.

Investigate the chemical profile differences among the obtained tomato genotypes from breeding program.

Study the possible correlation between accumulation of phenolic compounds and peroxidase anti-oxidant enzymes and tolerant potential of tested tomato varieties toward Fusarium wilt infection.

\section{Materials and Methods}

\section{Plants}

Seeds of fifteen tomato genotypes, (Solanum lycopersicum L,) which were obtained from a breeding program in addition to the commercial cultivar, Supper Strain B, which was cultivated in a wide spectrum in Egypt were sown in natural field located in
Gharbiya governorate, Egypt during 20132014. Normal agricultural practices i.e. fertilization and irrigation has been weekly followed. Different vegetative, flowering, fruiting, growth and quality criteria i.e. flowering time, plant height, number of branches, total yield, fruit weight, fruit firmness, and fruit shapes were recorded interval during growing seasons.

Eight weeks later, when the plants were about $55-60 \mathrm{~cm}$ in height, one leaf from four different plants in each genotype were cutoff from the plants and immediately stored in liquid nitrogen till subjected to the chemical analysis using HPLC apparatus.

\section{Bioassay and Tolerance Potentials of Tomato Genotypes}

For determining the tolerance potentials of the obtained tomato genotypes from the breeding program, surface sterilized seeds of the sixteen tomato genotypes, fifteen obtained from breeding program and one commercial variety (Super Strain B), were sown separately in plastic pots containing 1 $\mathrm{kg}$ sterilized sand : soil mixture $(1: 1 \mathrm{w} / \mathrm{w})$. After seed germination (approximately 6 days after sowing) inoculum of virulent Fusarium oxysporum isolate, obtained from plant pathology department, Faculty of Agriculture, Minufia University, was inoculated at rate of $10^{6} \mathrm{cfu} / \mathrm{g}$ soil and five replicates were treated to each individual tomato genotype.

Disease incidence and disease severity were recorded after 8 weeks from Fusarium inoculation according to Vakalounakis and Fragkiadakis (1999) based on 0 to 3 visual scale where:

$0=$ no symptoms

$1=$ light yellowing of leaves, light or moderate rot on tap root and secondary roots and crown rot 
$2=$ moderate or severe yellowing of leaves with or without wilting, stunting, severe rot on tap and secondary roots, crown rot with or without hypocotyls rot, and vascular discoloration in stem

$3=$ Dead plants.

Disease severity was determined using the following formula:

Disease severity $\%=$

$\left(\frac{(\Sigma \text { scale } x \text { number of plants infected })}{(\text { Highest scale } x \text { total number of plants })}\right) \times 100$

\section{Chemical Analysis}

Chromatogram analysis of tomato leaves collected from sixteen different tomato genotypes were performed on HPLC apparatus,( Agilent Technologies 1262 Infinity) system, using a preceded by a Eclipse plus ${ }^{\circledR} \mathrm{C} 18$ reversed phase guard column ( 4.6 by $10.0 \mathrm{~mm}, 3.5 \mu \mathrm{m}$ ). The HPLC system consisted of a 1260 Quat Pump unit, Agilent Technologies 1260 diode array detector, fluorescence array detector, and a 1260 auto sampler which were controlled by ChemoStation for LC 3D system.

Before samples injection, the column had been equilibrated with $90 \%$ (v/v) water and $10 \%$ Acetonitril (solvent B). After injection, the samples were eluted at a flow rate of 1.0 $\mathrm{ml} \mathrm{m^{-1 }}$ using an isocratic flow of $90 \%$ solvent $\mathrm{A}$ and $10 \%$ solvent $\mathrm{B}$ for $2 \mathrm{~min}$, a linear gradient to $10 \%$ solvent $\mathrm{A}$ and $90 \%$ solvent B for $28 \mathrm{~min}$, followed by an isocratic flow for 5 min with $90 \%$ solvent $B$. For conducting HPLC analysis, $4 \mathrm{~g}$ of fresh leaves collected from each genotype were freeze dried using liquid nitrogen. The Freeze-dried leaves were grinded using pestle and mortal before mixing thoroughly with $5 \mathrm{ml}$ of ethyl acetate in plastic test tubes and gently hand shacked for 15 min.

After shacking, the suspension was centrifuged at $12,000 \mathrm{rpm}$ for 3 minutes. After separation, the suspension was filtrated into new tubes through 2 cotton layers and evaporated under vacuum to completion. The extracted compounds were then dissolved in $250 \mathrm{ul}$ methanol and $50 \mu \mathrm{l}$ of each chemical extraction analyzed by HPLC. Spectral analysis was conducted to compare the detected peaks with similar retention times in all 1 oxtractions (Selim, 2010).

HPLC chemical standards of mixture of different chemical active compounds i.e. Acetone-DNPH, Acrolein-DNPH, 2, 5Dimethylbezaldehyde-DNPH,

Formaldehyde-DNPH, IsovaleraldehydeDNPH, Propionaldehyde-DNPH and peroxides were used as references to compare the spectra pattern of obtained peaks within tested tomato genotypes.

\section{Statistical Analysis}

Data were statistically analyzed according to standard analysis of variance by a one way ANOVA with the software statgraphics (Statistical Graphics. Crop, Rockville, MD), Variance homogeneity for all treatments according to Tukey test to compare differences between different treatments if the F-value was significant. Statistical differences referred to in the text were significant at $(\mathrm{P}<0.05)$ ( Selim 2010).

\section{Results and Discussion}

\section{Vegetative and Growth Criteria}

\section{Bioassay}

The results obtained from green house bioassay revealed that, all tested tomato genotypes were susceptible to Fusarium wilt disease. Significant differences were 
recorded among the tested varieties with regard to their tolerance potentials under the test conditions. The results showed that the highest disease severity was recorded on genotypes 16, 14 and 1, respectively (Fig.1). In contrary, the lowest percentage of disease severity was observed within genotypes No. $5,2,12$, respectively (fig.1).

\section{HPLC Analysis}

The accumulation of chemical compounds in tomato leaves was analyzed for activity using the array detector chromatogram at a wave length of $210 \mathrm{~nm}$. The differences between tomato varieties were determined based on the area under the curve of the peaks detected with retention time of 1.1 ; $33.1 ; 35.5 ; 37.1 ; 39.3 ; 43.0 ; 43.8$; and 44.6 min (Fig. 2). Similarity of the peaks detected with similar retention times within the tomato leaves of tested genotypes were also analyzed using spectral analysis.

The results showed that the highest accumulation of the chemical compounds particularly and specifically of those related to phenolic compounds were detected within the leaves of variety 5 followed by variety 2 , variety 6, variety 12 and variety 3 , respectively (fig.2).

Similar results were recorded with peroxides activity. Thus the highest accumulation of peroxidase was recorded again with genotype 5 followed by genotype 2 and genotype 3 , meanwhile the most susceptible genotypes were $15,1,14$, and 4 respectively (fig.3).

Table.1 Mean Performances of the Evaluated Breeding Genotypes for Some Plant and Fruit Characteristics in Tomato

\begin{tabular}{|c|c|c|c|c|c|c|c|c|}
\hline \multicolumn{2}{|c|}{ Genotypes } & $\begin{array}{c}\text { Days of } \\
50 \% \\
\text { flowering }\end{array}$ & $\begin{array}{l}\text { Pant } \\
\text { height } \\
\mathrm{cm} .\end{array}$ & $\begin{array}{l}\text { Number } \\
\text { of } \\
\text { branches }\end{array}$ & $\begin{array}{l}\text { Early } \\
\text { yield } \\
\text { k.g/ } \\
\text { plant }\end{array}$ & $\begin{array}{c}\text { Total } \\
\text { yield } \\
\text { kg./plant }\end{array}$ & $\begin{array}{l}\text { Average } \\
\text { fruit weight } \\
\text { gm. }\end{array}$ & $\begin{array}{c}\text { Fruit } \\
\text { Firmness } \\
\text { g/cm. }\end{array}$ \\
\hline \multicolumn{2}{|c|}{ S.2 } & 37.14 & 57.21 & 6.17 & 1.588 & 4.78 & 110.4 & 512.7 \\
\hline \multicolumn{2}{|c|}{ S.209 } & 35.86 & 65.81 & 8.25 & 1.42 & 3.167 & 142.17 & 581.6 \\
\hline \multicolumn{2}{|c|}{ PET-8 } & 34.19 & 43.16 & 5.61 & 1.125 & 3.22 & 75.67 & 605.3 \\
\hline \multicolumn{2}{|c|}{ END-1 } & 40.35 & 52.10 & 5.83 & 1.01 & 4.013 & 105.36 & 471.5 \\
\hline \multicolumn{2}{|c|}{ K.111-1 } & 40.11 & 68.13 & 8.5 & 1.315 & 6.445 & 135.72 & 572.1 \\
\hline \multicolumn{2}{|c|}{ K.111-6 } & 43.38 & 65.75 & 8.15 & 1.275 & 6.357 & 130.5 & 565.4 \\
\hline \multicolumn{2}{|c|}{ AL.3B } & 34.67 & 54.16 & 6.16 & 1.573 & 5.718 & 140.13 & 561.2 \\
\hline \multicolumn{2}{|c|}{ AL 3-1-3 } & 35.16 & 58.19 & 6.63 & 1.625 & 6.125 & 135.76 & 542.5 \\
\hline \multicolumn{2}{|c|}{ EUR.2-2 } & 32.6 & 67.13 & 7.1 & 1.58 & 6.51 & 130.5 & 536.1 \\
\hline \multicolumn{2}{|c|}{ STA.12.-12 } & 35.33 & 55.63 & 6.45 & 1.45 & 5.773 & 120.35 & 530.6 \\
\hline \multicolumn{2}{|c|}{ PO.16-3 } & 33.46 & 61.22 & 6.83 & 1.23 & 5.51 & 120.13 & 572.1 \\
\hline \multicolumn{2}{|c|}{ L.2 } & 44.28 & 150.33 & 14.25 & 0.905 & 6.55 & 110.63 & 460.5 \\
\hline \multicolumn{2}{|c|}{ ROC-2 } & 47.5 & 63.75 & 6.35 & 1.13 & 4.813 & 135.25 & 482.7 \\
\hline \multicolumn{2}{|c|}{ SMA-12 } & 41.12 & 51.16 & 5.47 & 1.215 & 4.725 & 165.67 & 375.6 \\
\hline \multicolumn{2}{|c|}{ GAP-16 } & 23.17 & 18.25 & 5.16 & 0.256 & 0.41 & 15.32 & 410.4 \\
\hline \multicolumn{2}{|c|}{ Mean } & 38.61 & 61.92 & 7.11 & 1.21 & 5.21 & 129.4 & 510.1 \\
\hline \multicolumn{2}{|c|}{ SSB* } & 38.67 & 55.17 & 6.53 & 1.32 & 5.713 & 135.63 & 592.7 \\
\hline \multirow[t]{2}{*}{ L.S.D } & $5 \%$ & 7.66 & 10.15 & 1.1 & 0.085 & 0.355 & 20.51 & 31.6 \\
\hline & $1 \%$ & 10.18 & 13.5 & 1.46 & 0.113 & 0.473 & 27.28 & 42.03 \\
\hline
\end{tabular}


Fig.1 Disease Severity Recorded after 8 weeks on Tomato Varieties (1:16) Inoculated Individually with Hyper Virulent Fusarium oxysporum Isolate under Green House Conditions. Paired Means with Different Error Bars are Significantly Different Based on STDV test $(\mathrm{p} \leq 0,05 ; \mathrm{n}=5)$.

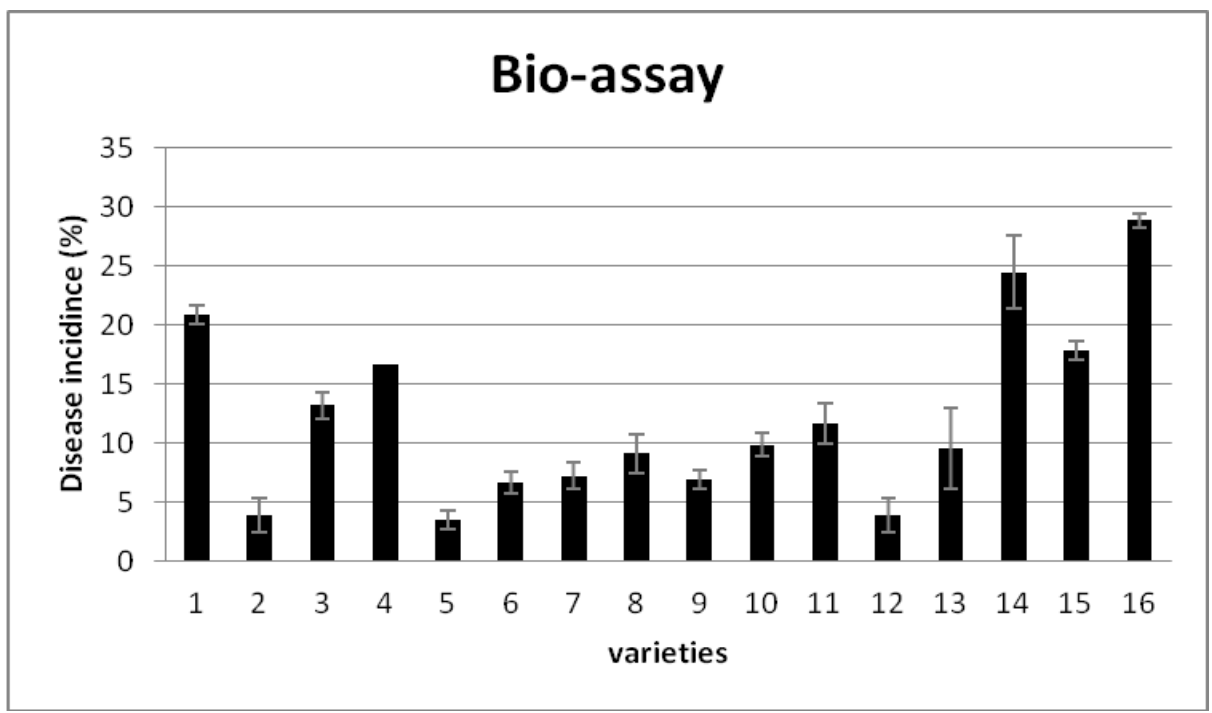

Fig.2 Accumulation of Peroxidase Detected at 210nm Wave Length in Leaves of Sixteen Different Tomato Genotypes Obtained from a Breeding Program.

\section{Total phenolics}

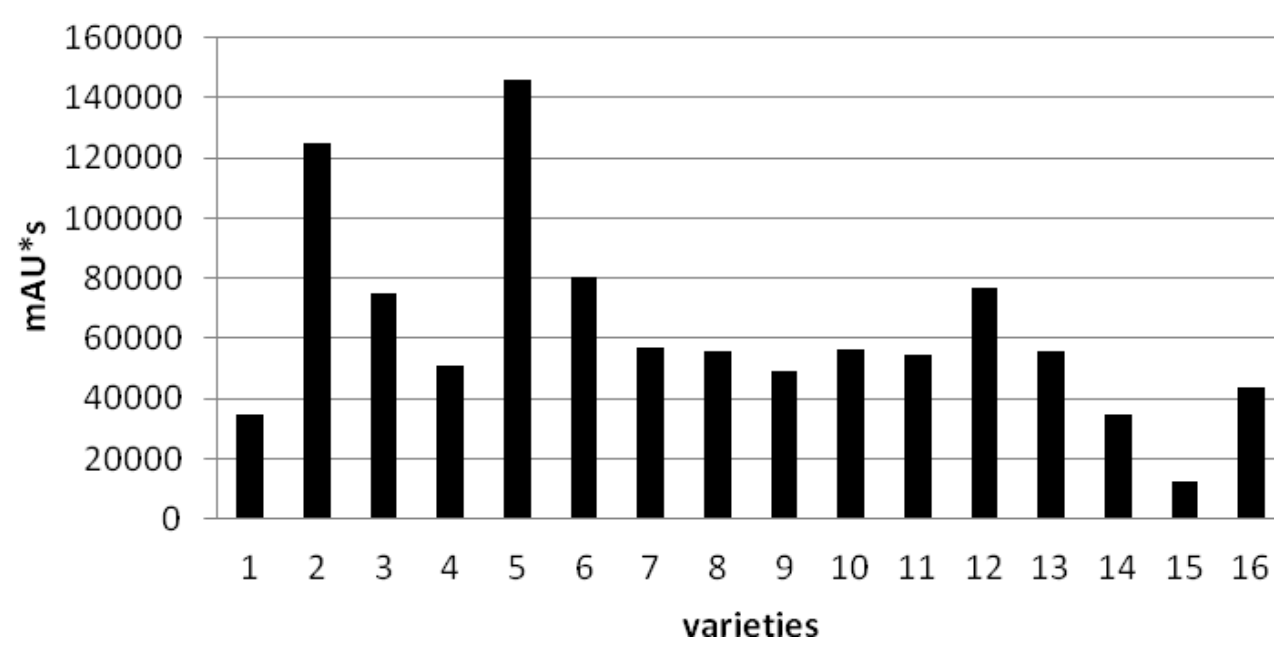


Fig.3 Accumulation of Phenolic Detected at 210nm Wave Length in Leaves of Sixteen Different Tomato Genotypes Obtained from Inbreeding Program.

\section{peroxidase activity}

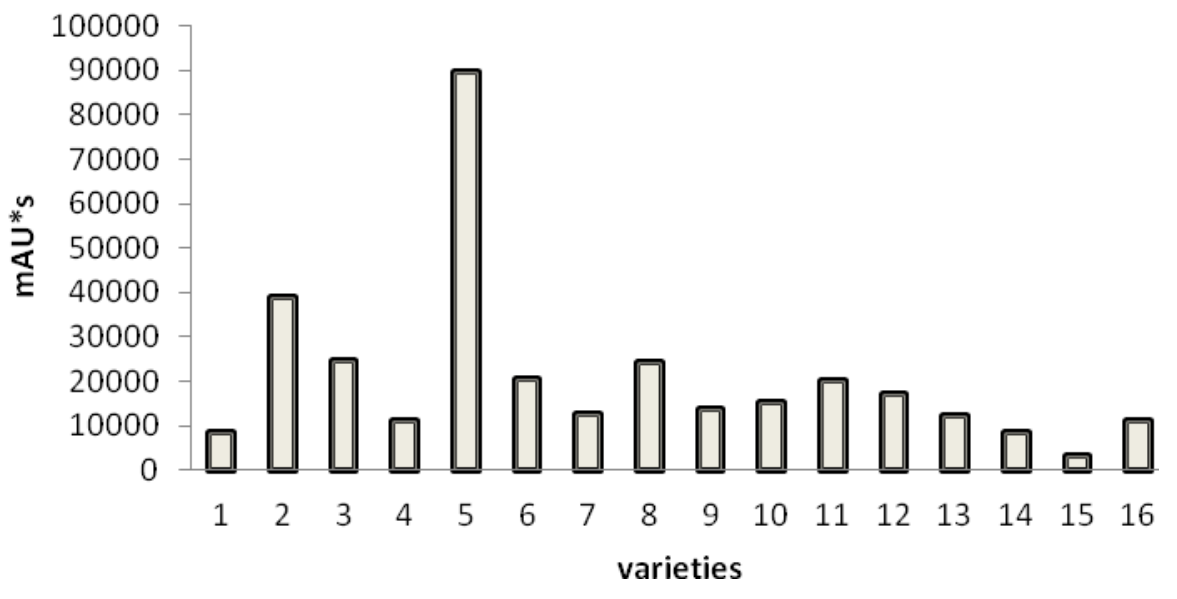

The aims for the present study was to determine the tolerance potential of fifteen different tomato genotypes obtained from inbreeding program toward the Fusarium wilt disease invasion under green house conditions. Furthermore, the chemical profile of the tested tomato genotypes was evaluated through using high performance liquid chromatogram analysis to figure out the possible chemical compounds that can be involved in the interaction between tomato genotypes and Fusarium oxysporum infestations as an example of the most destructive pathogen that attacks tomato plants and cause severe damage all over the world (Lasheen, 2009). However, these tested fifteen tomato genotypes were also compared with one commercial tomato variety which recently cultivated in the region where this study was conducted. The results showed that significant variation among all tested tomato genotypes were detected regarding to their vegetative characteristics and growth parameters i.e. fresh weight, plant height and fruit yield per plant which indicates the tolerance potentials against pathogens and parasites. The results illustrate that the highest weight as well as the highest yield was recorded with variety 5 followed by variety 2 and variety 6 , respectively, thus the total yield is the most important factor determines the success of breeding program.

Many studies have been carried out to elucidate the physiological and biochemical basis of host plant resistance rather than to understand the role of different chemical and biological compounds in controlling various plant diseases (Thukur and Sohal, 2013; Whitehead, 1998; Vakalounakis and Fragkiadakis, 1999.

In our present study, the results obtained from chemical analysis using HPLC revealed that there is an evidence of a positive correlation exists between the accumulation of a mixture of different chemical active compounds (i.e. AcetoneDNPH, Acrolein-DNPH, 2,5-Dimethylbezaldehyde-DNPH, Formal-dehyde-DNPH, Isovaleraldehyde-DNPH, PropionaldehydeDNPH) and the recorded biological and vegetative characters. It is remarkable that these results are consistence with the obtained results from bioassay test which 
showed that the highest accumulation of these chemical compounds was detected on the genotypes which showed the highest yield and vegetative values i.e. variety 5 variety 2 and variety 6.

These results were confirmed again when peroxides activity was determined using HPLC on leaves of the tested tomato varieties. The results demonstrated that the highest peroxides accumulation was detected again with leaves of variety 5 followed by variety 2 and variety 3 .

These results are similar to those obtained by Selim et al. (2014); Manzanilla et al., (2004), who reported that tomato systemic resistance can be activated either biologically or chemically by increasing the accumulation of different biochemical active compounds which one or more of them may affect the root-knot nematode infection and the physiological process of treated plants. In conclusion, phenolic and peroxidases compound are known to play a crucial role in controlling hazards pathogens and parasites that affecting the cultivation of economically important host plants through stimulating the defense mechanisms either direct or in directly(Thakur and Sohal, 2013).

\section{References}

Alabouvette, C., Schippers, B., Lemanceau, P., Bakker, P.A.H.M. 1998. Biological control of Fusarium wilts: Toward development of commercial products. Pages 16-36 in Plant-microbe interactions and biological control. G. J. Boland and L. D. Kuykendall, (Eds). Marcel Dekker, New York.

Costa, J.M., Heuvelink, E. 2005. Introduction: The tomato crop and industry. In: Heuvelink, E. (Eds.).
Tomatoes. CAB International, UK, pp. 1-19.

FAO. 2003. Agricultural statistics, Home page available at (http://apps.fao.org).

FAO. 2008. Agricultural statistics, Home page available at (http://apps.fao.org).

Fravel, D., Olivain, C., Alabouvette, C. 2003. Fusarium oxysporum and its biocontrol. New Phytol., 157: 493-502.

Fuchs, J.G., Moënne-Loccoz, Y., Défago, G. 1997. Non pathogenic Fusarium oxysporum strain Fo47 induces resistance to Fusarium wilt in tomato. Plant Dis., 81: 492-496.

Hussey, R.S., Janssen, G.J.W. 2002. Rootknot nematodes: Meloidogyne species. In: Starr, J. L., Cook, R., and Bridge, J. (Eds.) Plant resistance to parasitic nematodes, CABI UK. pp. 43-70.

Lasheen, H.H.A. 2009. Control of wilt disease of tomato through application natural compost and endomycorrhizal fungi. Ph.D. dissertation, Mansoura University, Faculty of Agriculture, Plant Pathology department.

Lukyanenko, A.N. 1991. Disease resistance in tomato. (In Kalloo, G., Genetic improvement of tomato. Springer. Veriag, Berlin, Heidelbe

Manzanilla-Lopez, R.H., Evans, K., Bridge, J. 2004. Plant diseases caused by nematodes. In: Chen, Z. X., Chen, S. Y. and Dickson, D. W. (Eds.). Nematology-Nematode management and utilization. Vol. 2, CABI Publishing, 637-703.

Noling, J.W. 2005. Nematode management on tomatoes, peppers and eggplant. Institute of Food and Agricultural Science, University of Florida. http://edis.ifas.ufl.edu/.

Roberts, P.A., Thomason, I.J. 1989. A review of variability in four Meloidogyne spp. measured by reproduction on several hosts 
including Lycopersicon. Agri. Zool. Rev., 3: 225-252.

Selim, M.E., Mahdy, M.E., Sorial, M.E., Dababat, A.A., Sikora, R.A. 2014. Biological and chemical - dependant systemic resistance and their significance for the control of rootknot nematodes. Nematol.

Sikora, R.A., Fernandez, E. 2005. Nematode parasites of vegetables. In: Luc, M. Sikora, R.A. \& Bridge, J. (Eds). Plant parasitic nematodes in subtropical and tropical agriculture. CABI Publishing: UK, pp. 319-392.

Thukur, M., Sohal, B.S. 2013. Role of elicitors in inducing resistance in plants against pathogen infection: A Review. ISRN biochemistry, volume 2013, Article ID 762412, Http://dx.doi.org/10.1155/2013/76241

2.

Vakalounakis, D.J., Fragkiadakis, G.A. 1999. Genetic diversity of Fusarium oxysporum isolates from cucumber: differentiation by pathogenicity, vegetative compatibility and RAPD fingerprinting. Phytopathol., 89: 161168.

Veremis, J.C., Roberts, P.A. 1996a. Relationships between Meloidogyne incognita resistance genes in Lycopersicon peruvianum differentiated by heat sensitivity and nematode virulence. Theoretical and Appl. Genetics, 93: 950-959.

Veremis, J.C., Roberts, P.A. 1996b. Identification of resistance to Meloidogyne javanica in the Lycopersicon peruvianum complex. Theoretical and Appl. Genetics, 93: 894-901.

Whitehead, A.G. 1998. Plant nematode control. CAB International, UK, pp. 384.

Williamson, V.M. 1998. Root-knot nematode resistance genes in tomato and their potential for future use. Ann. Rev. Phytopathol., 36: 277-293.

Yaghoobi, J., Kaloshian, I., Wen, Y., Williamson, V.M. 1995. Mapping a new nematode resistance locus in Lycopersicon peruvianum. Theoretical and Appl. Genetics, 91: 457-464.

\section{How to cite this article:}

Mosaad F. Ahmed, Hanafy A. Hamza, Ibrahiem A. Ibrahim, A.A. Nower and Mostafa Alansary. 2016. Biochemical Detection of Phenolic Compounds and Peroxidase in New Locally Improved Tomato Lines by using HPLC. Int.J.Curr.Microbiol.App.Sci. 5(5): 275-283. doi: http://dx.doi.org/10.20546/ijcmas.2016.505.030 